\title{
Research on the development strategy of reverse logistics of abandoned medicine in China
}

\author{
Hui-dan LIN ${ }^{l, a}$, Geng-jun GAO ${ }^{2, b}$
}

1 School of Economy \& Management, Shanghai Polytechnic University, Shanghai, 201209, China;

2 Logistics Research Center, Shanghai Maritime University, Shanghai, 200135, China;

ahdlin@sspu.edu.cn, b ggj_seu@163.com

Keywords: reverse logistics; abandoned medicine; outsourcing.

Abstract. This paper mainly introduces the types and features of abandoned medicine reverse logistics in China, as well as the causes of abandoned medicine reverse logistics. The paper also analyzed the problems existing in the abandoned medicine reverse logistics development in our country and analyzed to find out the solution.

\section{Introduction}

The development of reverse logistics of abandoned medicine is beneficial to economic benefit because recycling discarded drugs has great market and economic value. According to statistics, in the United States alone, only elderly patients lose $\$ 1$ billion in prescription drugs each year. Yet a good drug-recovery system can recycle $5 \%$ of prescription drugs, worth about $\$ 6$ billion a year. In addition, the enterprises participating in medical recycling can also reduce costs, tap new profit sources and increase customer satisfaction.

\section{Overview of reverse logistics of abandoned medicine}

So-called abandoned medicine reverse logistics is to regain its use value, or the right drug disposal of discarded drugs from hospitals, pharmacy, patients returned to the manufacturer or supplier to control and plan management process. In short, it's the process of abandoned drugs from the market to the enterprise.

\section{Types of reverse logistics of abandoned drugs}

Recycling drugs mainly includes the fake drugs, expired medicines, substandard drugs, because of the sales strategy adjustment, the pharmaceutical inspection institutions and decided not to change the packing specification, sample medicines back, etc. Among them, the main recycling activity is due to the specification, packaging change and the recycling. In addition, the source is concentrated in the vast majority of pharmaceutical consumers in the waste drug recycling, which is mainly through pharmacies, suppliers, wholesalers and other channels that are the opposite of the forward logistics. Pharmaceutical manufacturers can also carry out proper treatment of drugs according to the need, such as destruction, recycling and other sustainable methods.

\section{Characteristics of reverse logistics of abandoned drugs}

Difficult operation and management

According to the characteristics of medicine, equipment and resources needed for life cycle, the mode and process of medicine reverse logistics is different and complex, which results in more 
uncertainty in medicine reverse logistics in the process of production than the positive drug logistics.

Pharmaceutical variety, production batch number and tracking management of drugs have more strict requirements, different batch number represent different quality parameters, so relative to the forward logistics reverse logistics is haphazard; Moreover, the time, place and quantity of reverse logistics of drugs are unforeseeable, and the location is more dispersed and it is difficult to focus on one-off treatment.

Reverse logistics is diverse, which leads to a big difference of treatment methods. Some abandoned drugs need to reported loss, some for curing processing (such as medicine, slices, etc.), some need to landfill (such as chemical medicine, biological products, etc.), and some is to be broken up the packing for the sake of promotion needs. In the medicine circulation field in China, informationization condition is relatively backward and average management level is not high, drug terminal rendering "more, random, scattered, small" pattern, which not only brought a lot of difficulties to medicine forward logistics but also more multiple barriers of medicine reverse logistics development, increasing the difficulty of medicine reverse logistics channel management. Paroxysmal of some medicine reverse logistics

In addition to the urgent recall due to quality problems, reverse logistics has also become an important test for pharmaceutical enterprises. Because the occurrence of this kind of quality problem is emergent, the pharmaceutical industry is responsible for the major security risks in the process of procurement, production, sales and use. Emergencies emergency treatment is often the key to enterprise development prospect, which presents higher pharmaceutical enterprise management requirements and makes the pharmaceutical industry in the management of reverse logistics facing with more severe challenges.

Lack of attention

In China, our medicine enterprises paid attention to production sales and positive distribution link and medicine reverse logistics economic profit is not directly currently, such as consumer surplus drug treatment and failure of the drug, etc., are subject to more social forces to cooperate.

\section{Problems existing in the development of reverse logistics of abandoned medicine}

\section{Imperfect of reverse logistics system in the pharmaceutical industry}

In recent years, many pharmaceutical companies are committed to establish the forward drugs logistics system, not only training a large number of talents, but also spending a lot of money, however, they pay little attention to understanding of medicine reverse logistics. Therefore, most drug enterprises lack a set of effective reverse logistics system, which plays a key role in operation management system and information system, resulting in return and recovery difficulties and confusion. When medicine is returned to the enterprise or recycled, if it cannot be managed properly, it will bring huge losses to the enterprise. The reverse logistics system of the whole pharmaceutical industry cannot be effectively run, and it is difficult to find new profit sources, enhance customer satisfaction and enhance corporate image.

Traditional adverse drug logistics system involves complicated returned logistics activities from patients to pharmaceutical factory, to ensure the effective using of reverse medicine. Patients need to recycling, classification, drug inspection and reuse. The pharmaceutical factory needs to carry out 
recovery, classification, regeneration, waste disposal and so on, which will inevitably result in duplication of content, large human consumption, high cost, and possible duplication of transport, environmental pollution and other problems. No specification of return procedure for each node such as hospitals, social logistics companies and pharmacy and so on leads reverse logistics channel diverse and muddle of the current medicine reverse logistics in our country. Mostly most pharmaceutical companies carried out operations in accordance with the rules of warehousing, transportation and there is almost no special code for the medicine reverse logistics management in the national level.

\section{Unsound recovery model of waste medicine}

As the chart shows, there exists a considerable gap between the Chinese and foreign recycling medicine reverse logistics model. The main body in recycling of medicine reverse logistics is mainly led by the government and big business, which is by the pharmaceutical industry in China at present situation and the overall national quality. Sampling drug sampling is a high cost for enterprises, so various policies have been issued in various places to encourage enterprises to collect back samples to avoid waste of resources. As a profit-making organization, pharmaceutical enterprises are always the primary goal of obtaining the highest interest, but they should also take responsibility for the society. As a special commodity, the safety of medicine is closely watched by the people, but the process of reverse logistics is seldom known.

\section{Uncomplete recycling drug recovery method}

At present, there are four main kinds of medicine recycling methods in China. One is to recycle the medicine free of charge and the medicine box is set up by the pharmacy for the public to discard the expired medicine. The second is the collection of prizes, which are donated to the public by the pharmacy according to the value of recycling expired medicine. The third is to replace the old ones with new drugs and the public in exchange for the old ones produced by the factory. The forth is the proportion recovery. The drugstore distribute buy medicine voucher according to expired drug value $20 \% \sim 30 \%$ in certain limit and customers buy medicine by this coupon.

\section{Low awareness of the recycling discarded drugs by individuals}

Current understanding of abandoned medicine reverse logistics in our country is still relatively low and improving people's consciousness of the reverse logistics has a great role for the development of reverse logistics, even more important especially in recycle reverse logistics. In the present enterprise operation process, many people lack of understanding of abandoned medicine reverse logistics, even in the current collection, classification and management is also for economic benefit or to cope with the examination, but not really aware of the importance of abandoned medicine reverse logistics. In this case, the collection and management of abandoned medicine reflux content can't stick to it, once out of the regulation, people careless disposal of current drugs will involuntarily exposed.

\section{The development strategy of reverse logistics of abandoned drugs in China}

\section{strengthen the establishment and management of reverse logistics system of abandoned drugs}

Due to the particularity of drugs, compared other general commodity markets the drug market has the characteristics of non-liquid consumption, market demand fluctuation and lack of elasticity of demand. Therefore, establishment of reverse logistics system should fully consider the particularity of drug market and relevant laws and regulations in China.

According to the current situation of drug reverse logistics in China, it is necessary to establish an effective reverse logistics system. In other words, the reverse logistics model must be established. 
Drug return procedures include drug retreats, inspection and management, identifying quality problems and quality improvement phases.

Considering the distance economy and scale economy, it is the best choice to set up a special reverse logistics recycling center. The process standardization can save processing time cost and also facilitate pooling of enterprise information.

\section{Pharmaceutical enterprises shall combine the reverse logistics mode of joint venture and outsourcing}

Joint venture of reverse logistics for disused drugs

Associated patterns means cooperation by advantage enterprises of the pharmaceutical industry in the supply chain within a certain geographical area and establish a common reverse logistics system in the form of cooperation for the cooperative enterprises and even for the non-cooperative enterprises to provide convenient reverse logistics services. Because of much participating in the industry can reduce the degree of asset specificity of the reverse logistics system, which reduces a lot of pressure for a single enterprise on the investment of the reverse logistics system and also has professional advantages and easy to realize scale management. In view of the majority of pharmaceutical enterprises in China for small and medium-sized enterprises, it is recommended to adopt this mode, which is conducive to the core competitiveness of enterprises, and also provides outsourcing services to enterprises outside the alliance.

Outsourcing reverse logistics model of abandoned drugs

Because of particularity the pharmaceuticals and the higher demand for logistics the current pharmaceutical enterprises will reverse logistics outsourcing is hampered by large, but in the near future, people can gradually in-depth understanding of reverse logistics, third party logistics will play its proper in the pharmaceutical industry advantage

In combination with the present situation of China, the reasonable mode of reverse logistics of disused drugs is the combination of the combined mode and the third-party outsourcing mode. According to current pharmaceutical enterprise funds and the influence of the size in China, it is difficult to establish their own medicine reverse logistics center, then they should give full play to the power of the group, joint management mode, led by a strong enterprise in the industry and form a coalition to realize the scale operation as well as providing outsourcing services to un-attend the federation of small businesses at the same time. In the end, with the development of the reverse logistics in our country, the medicine reverse logistics theory will slowly mature and the third party logistics enterprise can step in to the medicine reverse logistics system to provide more professional service, and then pharmaceutical companies can also be used to put more effort into developing its core competitiveness so as to improve the competitive advantage of enterprises.

\section{Improving the recovery method of discarded drugs}

Recycling practices abroad is "who sold, recycling" , producers must consider any commodity recycling way and cost before production and sales of medicine is also not an exception. In the UK, expired medicine must be put in a garbage bag labeled "expired medicine". In Germany, the department of drug recycling is a major department dealing with expired drugs and has unified incineration of expired medicines. The method of compulsory recycling abroad makes every family a good recycling habit. Japan also has mandatory requirements for reclassification and reuse of its various materials because of resource problems. In view of China, the management of this piece is quite different from that of foreign countries. In China, there is a lack of compulsory recycling in addition to unpaid recycling, paid recycling, proportion recycling and old replacement. 


\section{Enhance people's awareness of reverse logistics}

At present, the international fashion "integrated waste management" is to mobilize all the public to participate in the $3 \mathrm{R}$ operation to reduce the total amount of discarded drugs. The three R's action slogans are: Reduce waste (Reduce); Recycle (Recycle); Use Reuse. Because economic globalization and social resources tend to flow globally, the whole society needs to do so to reduce the amount of discarded drugs and the burden of urban disposal of these discarded drugs. Therefore, we must strengthen to the people abandoned medicine reverse logistics knowledge training and popularization to make them truly realize the importance of reverse logistics, realize reflux content value and importance of environmental protection.

\section{Conclusion}

Abandoned medicine reverse logistics is a very important competitive edge tool, especially in the globalization medicine reverse logistics status in the enterprise's business model has been more and more important, which can bring huge economic benefits to the enterprise and the huge potential market. Under the premise of national perfect law, it is impossible to carry out expired drug recovery relying solely on the efforts of a certain enterprise. Only the combination of the pharmaceutical industry upstream and downstream enterprises, the use of information technology effectively, improve the citizens' environmental protection consciousness, to learn from the effective information in forward logistics, and formulate appropriate scrap recycling medicine reverse logistics mode and improve the abandoned medicine reverse logistics system. On this basis, it will be simpler, more convenient and more efficient to reverse logistics.

\section{Acknowledgement}

This research was supported by Training of Young Teachers' Scientific Research Project for 2017(B50YC150005P4).

\section{Reference}

[1] Yuan fang, Qiu jixue. Developing reverse logistics to improve pharmaceutical logistics system [M]. Western pharmacy, 2007.

[2] Wei wei. Talk about the recovery and countermeasures of expired drugs [J]. Medical information, 2011.3405-3406.

[3] Han weilian. The harm and recovery of expired drugs [J]. China contemporary medicine, 2010,(29):156.

[4] Xiao chun, Zou xuelian. Obstacles and countermeasures for the development of drug reverse logistics in China [J]. Logistics technology. 2006, (10).

[5] Hou yanhong, Congmeng. Comparative study on the topological structure of pharmaceutical supply chain in China and the United States [J]. Current management science, 2014, 4.

[6] Huang chi-wei. The next five years of pharmaceutical circulation: the birth of a world-class big $M A C[\mathrm{~J}]$. China journal of pharmaceutical industry, 2014, 4:48.

[7] Wang shu-min, Hu tianjun. A SWOT analysis of reverse logistics development in China [J]. Logistics technology journal 2010,9:27-30.

[8] Shu liang, Liu xiangli. The application of game theory in guiding enterprises to implement 
recycling reverse logistics [J]. China market journal, 2012,23:45-47.

[9] $\mathrm{Xu}$ xiaogang, $\mathrm{Xu}$ xiaogang. The study on the green degree of reverse logistics system [J]. Modern journal of shopping mall, 2011,9:150-151.

[10] Pangao lei, Li jie. SWOT analysis on the development of military reverse logistics [J]. Logistics engineering and management journal, 2010,10:111-112.

[11] Li Tingting. A brief discussion on the reverse logistics of abandoned drugs [J]. Cooperative economy and technology. 2009(17).

[12] Zhang xi. Application of reverse logistics in the pharmaceutical industry [D]. Undergraduate thesis of shenyang pharmaceutical university, tutor: Meng ling, 2007.

[13]Borissov. Harmonization of pharmaceutical regulation between CADREAC and the European Union[J].WHO Drug Information,2012,164,16(4) : 27.

[14]Stephen E.Mussona and timothy G.Townsend. Pharmaceutical Compound countent of municipal solid waste.Journal of Hazardous Materials.[J]Volume 162,ISSUE 2-3,MAR,2013,Pages 730-735.

[15]Kolpin D W,Furlong E T \&Meyer M T ,et al. Pharmaceuticals, Hormones, and Other Organic wastewater Contaminants in U.S.Streams,1999-2000:Anational Reconnaissance[J].2013,36 : 1202-1211. 